\title{
Cell-mediated immunity in patients with cystic fibrosis
}

\author{
A GIBBONS, J D ALLAN, A HOLZEL, H McFARLANE
}

British Medical fournal, 1976, 1, 120-122

minutes and the supernatant precipitated with $50 \%$ ammonium sulphate, followed by centrifugation at $4^{\circ} \mathrm{C}$ for 30 minutes at 4000 rpm. The precipitate was resuspended in PBS, dialysed overnight, then filtered through Whatman Glass Fibre paper GF/C $2.5 \mathrm{~mm}$ When required for use in the leucocyte migration test each tissue antigen was diluted with minimum essential medium (MEM) for tissue culture containing 1000 IU penicillin and 1000 IU streptomycin to give a final protein concentration of $600 \mathrm{mg} / \mathrm{l}$.

Other antigens-A fumigatus, Ps aeruginosa, and whole-egg antigens and 18 healthy controls were investigated by migration inhibition induced by a variety of antigens. In patients with CF cell-mediated immunity was found to human lung and pancreatic tissue extracts as well as to $A s p e r-$ gillus fumigatus, Pseudomonas aeruginosa, and food antigens but not to brain, heart, or kidney. Those patients with the severest form of the disease had the greatest impairment of cell-mediated immunity, but this impairment could be reversed by steroid treatment. Cellmediated cytotoxicity may also be concerned in the pathogenesis of CF.

\section{Introduction}

The cause of the pathological changes seen in patients with cystic fibrosis (CF) remains uncertain. Circulating serum autoantibodies and localised autoantibodies in the sputum to human pancreas and lungs in patients with CF have been reported. ${ }^{2}$ Other workers have observed pulmonary infiltrations due to chronic allergic aspergillosis ${ }^{3}$ and have shown that about $31 \%$ of patients with CF have serum precipitins to Aspergillus fumigatus $^{4}$ as well as a positive type I immediate and type III delayed hypersensitivity to the same fungal antigen. The possibility has therefore been raised that these antibodies produced to $A$ fumigatus may have a causal relationship to the lung damage seen in patients with CF. ${ }^{5}$ Not only are there type I and type III hypersensitivity reactions to $A$ fumigatus, however, but it seems that many patients with CF may have type I and type III hypersensitivity reactions to a variety of antigens, including food, bacteria, fungi, human body tissue, and common allergens. ${ }^{6}$ Our report is concerned with cell-mediated immunity to a variety of antigens in patients with $C F$.

\section{Patients and methods}

Twenty-six patients (15 males and 11 females aged 8 months to 19 years) with $C F$ were investigated. The clinical diagnosis of $C F$ was confirmed by a sweat chloride concentration above $70 \mathrm{mmol} / 1$ ( 70 $\mathrm{mEq} / \mathrm{l})$. Eleven blood donors and seven children aged 3 to 11 years served as controls.

Tissue antigens-Lung, pancreas, brain, kidney, and heart were obtained at necropsy from an 8-year-old girl who had had CF and from another 8-year-old girl who had shown no evidence of CF and were stored at $-70^{\circ} \mathrm{C}$ until required for use. Each piece of tissue was thoroughly rinsed with cold phosphate buffered saline (PBS) ph $7 \cdot 2$ and then homogenised in an equal volume of PBS at $4{ }^{\circ} \mathrm{C}$ for two minutes using a Sorvall Omnihomogeniser. After standing for 30 minutes at $4{ }^{\circ} \mathrm{C}$ the homogenate was centrifuged at $3500 \mathrm{rpm}$ for 30

\footnotetext{
Department of Medical Biochemistry, University of Manchester, Manchester M13 9PT

A GIBBONS, BSC, research assistant

H MCFARLANE, PHD, MRCPATH, senior lecturer in chemical pathology

Macclesfield Hospital, Macclesfield, Cheshire

J D ALLAN, MD, MRCP, consultant paediatrician

Department of Child Health, University of Manchester, Manchester A HOLZEL, MD, FRCP, professor emeritus
} were obtained from Bencard, Brentford, England. Bovine serum albumin (BSA) was obtained from Sigma Chemical Company, St Louis, USA.

Dose response-The final concentration of each antigen used in the migration inhibition tests was determined by dose response curves as shown in fig 1 . Subsequently each antigen was diluted in MEM and used at a final protein concentration of $250 \mathrm{mg} / \mathrm{l}$.

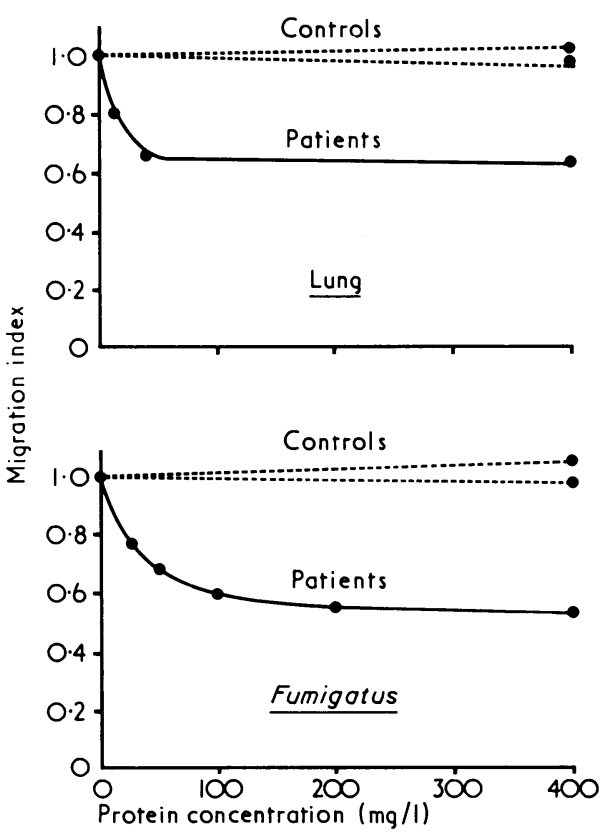

FIG 1-Dose response of $\mathrm{MI}$ of leucocytes from both patients and controls to different concentrations of lung antigen and $A$ fumigatus.

Migration index $(M I)-10 \mathrm{ml}$ of heparinised blood from the patients and the controls was sedimented in $16 \%$ dextran under sterile conditions for 60 minutes at $37^{\circ} \mathrm{C}$. The leucocyte-rich supernatant was centrifuged at $1500 \mathrm{rpm}$ for five minutes. The cell pellet was washed three times with $M E M$ and resuspended to a concentration of $5 \times 10^{\circ}$ cells $/ \mathrm{ml}$ in the medium. About $1 \times 10^{6}$ cells were drawn into Microcap 20- $\mu$ l capillary tubes. After sealing one end the cells were packed by centrifugation at $2000 \mathrm{rpm}$ for five minutes. Each capillary tube was then squarely cut across the cell fluid interfaces and secured by silicone grease in Sterilin microchambers, which were then filled with MEM with or without antigens, sealed with microcoverslips, and incubated at $37^{\circ} \mathrm{C}$ for 18 hours. Each test and control was carried out in quadruplicate and the mean area of migration calculated. The $\mathrm{MI}$ was calculated from the area of migration in the presence of antigen divided by the area of migration in the absence of antigen; an $\mathrm{MI}$ above 0.85 was considered normal. ${ }^{7}$

Inhibition of migration of guinea-pig peritoneal macrophages-The macrophage-inhibition factor produced from the inhibition of migration of CF leucocytes by antigens was confirmed with further migration tests with guinea-pig macrophages according to a modified method. ${ }^{8}$ For each experiment at least two guinea-pigs were injected 
interperitoneally with $20 \mathrm{ml}$ of sterile liquid paraffin. Four days later the guinea-pigs were killed and the macrophages immediately harvested by perfusion of the peritoneal cavity with $250 \mathrm{ml}$ of sterile MEM. The macrophages were then washed four times with the same medium, pooled, and about $1 \times 10^{6}$ cells were packed into Microcap 20- $u$ l capillary tubes before proceeding as outlined above. The guineapig peritoneal macrophages were allowed to migrate with $(a)$ medium alone, $(b)$ medium plus antigen, and $(c)$ medium plus positive (or negative) leucocyte migration-inhibition culture fluid.

\section{Results}

The results are summarised in table $I$ and their distributions are shown in fig 2 .

TABLE I-Mean leucocyte migration indices $( \pm S D)$ to some antigens. Number of patients tested are given in parentheses

\begin{tabular}{|c|c|c|c|c|}
\hline \multirow{2}{*}{ Subjects } & \multicolumn{2}{|c|}{ Extract of CF } & \multirow{2}{*}{ A fumigatus } & \multirow{2}{*}{ Ps aeruginosa } \\
\hline & Lung & Pancreas & & \\
\hline $\begin{array}{l}\text { Patients } \\
\text { Controls }\end{array}$ & $\begin{array}{l}0.75 \pm 0.18(21) \\
1.02 \pm 0.08(16)\end{array}$ & $\begin{array}{l}0.71 \pm 0.14(10) \\
1.06 \pm 0.11(6)\end{array}$ & $\begin{array}{l}0.69 \pm 0.17(17) \\
0.96 \pm 0.14(13)\end{array}$ & $\begin{array}{l}0.68 \pm 0.13(14) \\
0.99 \pm 0.17(10)\end{array}$ \\
\hline $\mathbf{P}$ & $<0.01$ & $<0.01$ & $<0.01$ & $<0.01$ \\
\hline
\end{tabular}

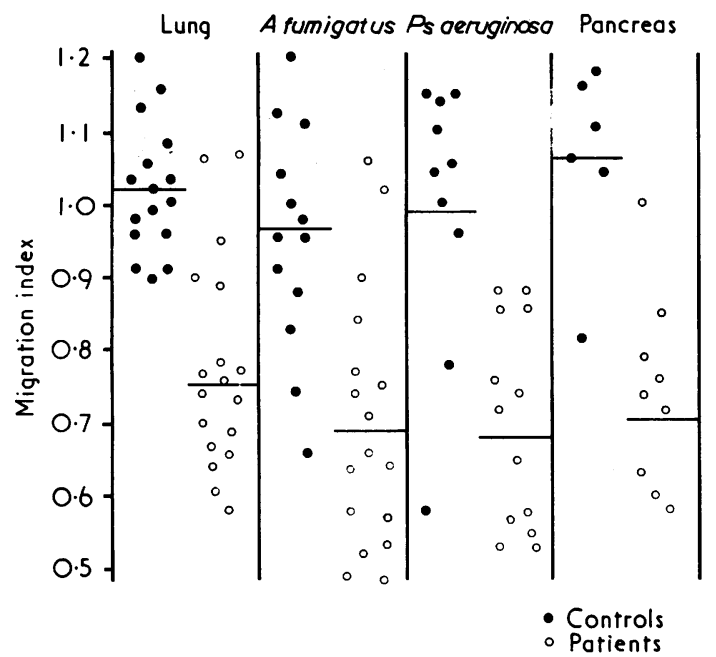

FIG 2-Distribution of MIs induced by lung, $A$ fumigatus, Ps aeruginosa and pancreatic antigens in patients and normal controls.

MI induced by antigenic extract of human tissues-The MI induced by antigenic extracts from both CF lung and pancreas showed that there was a significant inhibition of migration of the leucocytes from patients with CF but not of those from the controls. Fractionation of the antigenic extract from CF lung by molecular sieving through Sephadex G200 gel showed that the leucocyte migration inhibition antigen was eluted from the column in the first peak, suggesting that it was a fraction of relatively high molecular weight. Six patients with $\mathrm{CF}$ who showed a decreased MI to CF lung extract also showed a decreased MI to normal human lung extract, indicating that the lung antigen may not be confined to CF lung only. One patient showed normal MI to both $\mathrm{CF}$ lung and normal lung tissue extracts. Leucocytes from four patients who showed a decreased MI to antigenic extracts from lungs, pancreas, and $A$ fumigatus showed no such decreased MI to antigenic extracts from heart muscle, kidney, or brain.

$M I$ induced by antigens to $A$ fumigatus and Ps aeruginosa-Of the patients with CF $75 \%$ had MI values induced by $P$ s aeruginosa antigen less than 0.8 and only four out of 17 patients had MI values induced by $A$ fumigatus that were above $0 \cdot 8$, the rest being significantly lower than the mean values of the controls.

$M I$ induced by BSA and egg white-Two out of four patients with CF showed greatly decreased MI values to BSA and all four showed decreased values to whole-egg antigens. None of the three controls tested showed any decrease in the MI values when tested against BSA and whole-egg antigens.
Effects of steroids on MI-Table II shows that after three patients with CF were treated for three days with prednisolone $5 \mathrm{mg}$ four times a day by mouth their initial decreased MI induced by antigenic extract from lung, pancreas, $A$ fumigatus, and $P$ s aeruginosa showed a significant $(\mathrm{P}<0.001)$ return to normal within three days.

TABLE II-Leucocyte migration indices for three patients with CF against five antigens before and after patients were given prednisolone $5 \mathrm{mg}$ four times a day by mouth. Age and sex of patients is given

\begin{tabular}{l|c|c|c|c|c|c}
\hline & \multicolumn{2}{|c|}{$\begin{array}{c}\text { Case 1 } \\
\text { (11 years F) }\end{array}$} & \multicolumn{2}{c|}{$\begin{array}{c}\text { Case 2 } \\
\text { (16 years F) }\end{array}$} & \multicolumn{2}{c}{$\begin{array}{c}\text { Case 3 } \\
\text { (17 years F) }\end{array}$} \\
\cline { 2 - 3 } & Before & After & Before & After & Before & After \\
\hline CF lung & 0.94 & 1.16 & 0.72 & 1.11 & 0.82 & 1.30 \\
Normal lung & 0.74 & 1.03 & 0.86 & 1.08 & 0.74 & 1.08 \\
CF pancreas & 0.82 & 1.07 & 1.10 & 1.11 & 0.80 & 1.16 \\
A fumigatus & 0.90 & 1.03 & 0.85 & 1.04 & 0.88 & 1.13 \\
Ps aeruginosa & 0.72 & 1.08 & 0.90 & 1.08 & 0.74 & 1.09 \\
\hline
\end{tabular}

Inhibition of guinea-pig macrophages-The migration of guinea-pig macrophages was inhibited by the supernatants from those experiments in which the migration of CF leucocytes was inhibited by the antigen, indicating that a macrophage-inhibition factor was produced by the inhibited leucocytes. Guinea-pig macrophages were not, however, inhibited by either the supernatants from normally migrating leucocytes or antigen alone.

\section{Discussion}

Inhibition of $\mathrm{CF}$ leucocyte migration was strongly induced by both normal and CF lung and pancreatic tissue extracts, which suggested that cell-mediated immunity to these tissue antigens does exist in CF. The significance of this cell-mediated immunity to lung and pancreatic tissue antigen in CF is obscure but possibly it may be related to the damage of these organs in CF. Fractionation of the lung antigen by molecular sieving through Sephadex G200 columns suggested that the lung antigen was of relatively high molecular weight. But whether this is related to the circulating immune complexes described in CF is not known. ${ }^{6}{ }^{9}$ No leucocyte migration inhibition could be detected by antigenic extracts from heart, muscle, kidney, or brain.

CF leucocyte migration induced by $A$ fumigatus and $P s$ aeruginosa antigens was also inhibited significantly, suggesting that the pulmonary infiltration associated with these organisms may be partly cell-mediated. Moreover, the initial damage to the lung in CF is probably caused by the overwhelming infection from fungi and bacteria and once the infections are established the lung damage becomes progressively worse because of the increasing role of cell-mediated immunity induced by both host tissue antigens and antigens of the invading organisms. The production of macrophage-inhibition factors by CF leucocytes that were inhibited by the different antigens supports the evidence for the presence of cell-mediated immunity.

Several workers have reported a high percentage of positive serum and sputum precipitins to a variety of antigens ${ }^{1011}$ and it seems that these precipitins are mediators of a type III Arthus reaction in patients with CF. Our findings suggest that cellmediated immunity to a similar wide variety of antigens may also exist in CF and that a type IV cytotoxic reaction may also be a prominent feature in the pathogenesis of CF.

The various hypersensitivity reactions classified by Gell and Coombs $^{12}$ include the following: (1) The type I immediate hypersensitivity (anaphylactic) reaction found in about $40 \%$ of patients with $\mathrm{CF}^{13}$ is IgE dependent and, along with specific allergen, is responsible for the release of various vasoactive substances including histamine. (2) The type II cytotoxic reaction is cell-mediated and in the presence of sensitised cells, antigen, and sometimes complement severe tissue damage may occur. (3) In the type III Arthus hypersensitivity reaction circulating toxic immune complexes formed between excess antigen and antibody with or without complement are responsible for 
tissue damage, this reaction has also been described in patients with CF. (4) The type IV delayed hypersensitivity reaction described in this paper is mediated by allergised cells.

In our patients but not in our controls there was a positive correlation between the MIs induced by $(a)$ lung and pancreatic tissue antigen $(\mathrm{r}=0.76),(b)$ lung and $A$ fumigatus $(\mathrm{r}=0.88)$, (c) lung and Pseudomonas $(\mathrm{r}==0.50)$ and $(d)$ Ps aeruginosa and $A$ fumigatus $(\mathrm{r}=0.86)$. The correlation coefficients between the MI induced by pancreatic tissue antigen and those induced by the other antigens were lower. The significance of these observations is not clear but there may be some common antigenic determinants giving rise to cross reactivity between lung and pancreatic tissue and between lung and $A$ fumigatus and $P s$ aeruginosa.

Most patients with CF who showed a greatly reduced MI to one antigen also showed a similarly reduced MI to the other antigens and although there were only a few patients in this study these results suggest that those patients who had the most severe condition also had the greatest reduction of their MI. In those patients with CF who responded well to prednisolone treatment their initially depressed MI returned to normal, which suggests that impaired cell-mediated immunity plays a part in the pathogenesis of CF. It seems, therefore, that investigation of the leucocyte MI to different antigens is of some benefit in the management of patients with $C F$.
We thank the Cystic Fibrosis Research Trust and the North-western Regional Health Authority for their support for this work.

Requests for reprints should be addressed to $\mathrm{Dr} \mathrm{H}$ McFarlane.

\section{References}

${ }^{1}$ Murray, M J, and Thal, A P, Annals of Internal Medicine, 1960, 53, 548.

2 Stein, A A, et al, fournal of Pediatrics, 1964, 65, 495.

${ }^{3}$ Mearns, M, Young, W, and Batten, J C, Thorax, 1965, 20, 385.

${ }^{4}$ Mearns, M, Longbottom, J L, and Batten, J C, Lancet, 1967, 1, 538.

${ }^{5}$ Warren, C P W, et al, Clinical Allergy, 1975, 1, 1.

${ }^{6}$ McFarlane, H, et al, British Medical fournal, 1975, 1, 423.

${ }^{7}$ S $\phi$ borg, M, and Bendixen, G, Acta Medica Scandinavica, 1967, 181, 247.

${ }^{8}$ Morley, J, Wolstencroft, R A, and Dumonde, D C, in Handbook of Experimental Immunology, ed D M Weir, vol 2, chap 28, p 20. Oxford, Blackwell, 1973.

${ }^{9}$ Pepys, J, et al, Proceedings of the 6th International Congress Allergology, ed B Rose, et al, p 221. Amsterdam, Excerpta Medica, 1968.

10 Wallwork, J C, et al, Clinical and Experimental Immunology, 1974, 18, 303.

${ }^{11}$ Cracco, G, et al, 5th Annual Meeting of the European Working Group for Cystic Fibrosis, Verona, Italy, 22-23 April 1974.

${ }^{12}$ Gell, P G H, and Coombs, R R A, (editors), Clinical Aspects of Immunology, 2 edn, p 588. Oxford, Blackwell, 1967.

${ }^{13}$ McFarlane, H, et al, Cystic Fibrosis News, 1975, 10(2), 6.

\title{
Role of doxapram in reducing pulmonary complications after major surgery
}

\author{
T H GAWLEY， J W DUNDEE， P K GUPTA， C J JONES
}

British Medical fournal, 1976, 1, 122-124

\begin{abstract}
Summary
In a double-blind study patients given a single dose of doxapram $1.5-2.0 \mathrm{mg} / \mathrm{kg}$ combined with morphine postoperatively had a significantly lower incidence of reflex postoperative cough and expectoracion of purulent sputum than patients given morphine alone. They also had significantly higher arterial oxygen tensions five days postoperatively. Smaller differences were found with naloxone combined with morphine.
\end{abstract}

\section{Introduction}

Despite advances in anaesthesia respiratory complications and some degree of hypoxia may still occur after upper abdominal operations. Many attempts have been made to solve this problem, and the various approaches used indicate basic lack of understanding of the factors involved.

In a study of the clinical and pharmacological effects of morphine combined with either the respiratory stimulant doxapram or the opiate antagonist naloxone Gupta and Dundee ${ }^{12}$

Queen's University Hospital and Royal Victoria Hospital, Belfast

T H GAWLEY, MD, FFARCS, consultant anaesthetist (present address: Belfast City Hospital)

$J$ W DUNDEE, MRCP, FFARCS, professor of anaesthetics

P K GUPTA, MD, DA, associate professor (present address: Banaras Hindu University, Varanasi-5, India)

C J JONES, BPHARM, MPS, clinical research associate (present address: A H Robins Company, Horsham, Sussex) noted a lowered incidence of postoperative pulmonary complications in those patients given doxapram. In that study respiratory complications were taken as the occurrence of coughing or the expectoration of purulent sputum or both during the first postoperative week. This surprising finding was considered to be of such clinical significance that a more detailed study using more objective methods of assessment of respiratory complications was undertaken in the same centre. We report here the findings in a further 95 patients recovering from upper abdominal operations and analyse the pooled data for both series, which totalled 235 patients.

Patients included in the study were those having routine postoperative analgesia with intravenous morphine alone or combined with a respiratory stimulant dose of doxapram. Naloxone was also given with morphine, since it was included in the original study ${ }^{1}$ and is widely recognised as the best available opiate antagonist.

\section{Methods}

Patients aged 16-60 years recovering from upper abdominal operations participated. They were visited before their operation, and consent was obtained for respiratory function tests and arterial blood sampling. The respiratory function tests, consisting of forced vital capacity (FVC), forced expiratory volume in one second $\left(F E V_{1}\right)$, and peak expiratory flow rate (PEFR), were carried out with a Monaghan electronic pulmonary function analyser, type $M 403 .^{3}$ Blood samples were taken at the same time from the radial artery into heparinised syringes and stored in an ice container for not more than 15 minutes before blood oxygen and carbon dioxide tensions were determined with a Cambridge EIL 48C analyser. All patients had a thorough physical examination. Those admitted to the study had a preoperative arterial oxygen tension $\left(\mathrm{PaO}_{2}\right)$ of over $10.6 \mathrm{kPa}(80 \mathrm{~mm} \mathrm{Hg})$ when breathing air and had no evidence of pulmonary or cardiovascular disease. 